\title{
BALANÇO DOS ESTUDOS SOBRE OS CONSELHOS DE POLÍTICAS PÚBLICAS NA ÚLTIMA DÉCADA*
}

Carla Almeida, Domitila Costa Cayres

e Luciana Tatagiba

Desde o final da década de 1980, como resultado das exigências da Constituição Federal de 1988 e do forte ideário participativo que marcou o processo de transição do regime militar ao democrático no país, os espaços institucionais de participação tornaram-se elementos marcantes do sistema político brasileiro. Tendo em vista a novidade que representaram e a magnitude que adquiriram na democracia brasileira, não surpreende que, ao longo das três últimas décadas, eles tenham se tornado foco crescente do interesse de diversos pesquisadores, num processo contínuo de consolidação dessa área de estudos.

Este artigo tem como objetivo fazer uma revisão de parte dessa literatura, para buscar mapear e descrever a produção acadêmica nacional sobre os conselhos de políticas públicas, entre 2000 e 2011. Elegemos os conselhos como objeto dessa análise tendo em vista sua

- Esse trabalho foi elaborado no quadro da pesquisa "Diagnóstico e Análise da Produção Acadêmica sobre Conselhos Gestores de Políticas Públicas no Brasil”, que contou com o apoio financeiro do CNPq. 
importância como modelo participativo e sua capilaridade em todo o território nacional. Escolhemos como marco a década de 2000 por ser um momento de consolidação dos conselhos de políticas públicas como parte da arquitetura institucional do Estado brasileiro e, também, de sua expansão na esfera federal ${ }^{1}$. No campo acadêmico das ciências sociais, esse é também um período no qual a temática da participação ganha reconhecimento como área de estudo relevante no debate sobre a democracia ${ }^{2}$.

Nosso estudo analisa o conjunto da produção sobre os conselhos, recuperando tendências e perfis gerais. Mas, ao mesmo tempo, também buscamos identificar as especificidades desse debate nos quatro campos de conhecimento que mais têm produzido sobre o tema: ciências sociais, saúde, serviço social e educação. No geral, os balanços sobre a literatura dos conselhos têm 256 ficado restritos aos seus campos disciplinares. Aqui buscamos olhar para além das fronteiras, reconhecendo e comparando as contribuições dos diferentes olhares sobre o mesmo objeto, partindo de nosso campo de origem: as ciências sociais. Nossa expectativa é de que essa comparação nos permita ver com mais clareza os avan-

\footnotetext{
1 Para informações sobre os conselhos criados e reformulados a partir de 2003, ver publicação da Secretaria-Geral da Presidência da República (Brasil, 2011) e IPEA/DIEST (2013).

2 Vale mencionar que o GT Controles Democráticos da Anpocs, criado em 2001, veio abrigando, nas suas diversas edições desde então, boa parte dos estudos referentes aos conselhos e outros espaços de participação, indicando o reconhecimento adquirido pelo tema nas ciências sociais. Nessa direção, vale mencionar que a análise de Arantes e Reis (2010) mostrou que, nos seus dez anos de funcionamento, em meio à grande diversidade de temas e problemas abrigados no GT, a participação apareceu como a palavra-chave mais frequente no conjunto dos trabalhados apresentados. Cabe ainda lembrar que, em 2012, a Associação Brasileira de Ciência Política (ABCP) criou o GT Participação Política, deixando evidente mais uma vez a importância que a temática assumiu nas ciências sociais.
} 
ços e as lacunas que caracterizam o nosso conhecimento sobre o tema dos conselhos, e contribuir, assim, com a conformação de novas agendas de pesquisa. No caso das ciências sociais, esperamos contribuir com um dos temas hoje centrais na agenda de pesquisa das instituições participativas, que é a relação entre participação e políticas públicas, uma associação comparativamente mais forte nos outros três campos disciplinares por motivos óbvios.

Nosso universo de análise contempla artigos, dissertações e teses sobre os conselhos de políticas públicas, oriundos de diversas áreas de conhecimento ${ }^{3}$, coletados em bancos de dados específicos para um intervalo de tempo definido: de 2000 a 2011. As dissertações e teses foram coletadas nos bancos on-line da Capes (Coordenação de Aperfeiçoamento de Pessoal de Nível Superior) e do IBICT (Instituto Brasileiro de Informação em Ciência e Tecnologia). Os artigos foram coletados na base do Scielo $\mathrm{Br}^{4}$. Para todos os tipos de produção, adotamos como procedimento de busca a inserção das palavras conselho/conselhos nos links disponíveis para esse fim. Diante da lista resultante dessa primeira busca, um segundo filtro foi adotado, de modo a selecionar apenas produções que tratavam dos conselhos de políticas públicas $^{5}$. Para ser inserida no nosso universo, a produção

\footnotetext{
3 Conhecemos apenas um trabalho semelhante ao que apresentamos aqui. Trata-se do balanço feito por Gugliano (2005) da produção de dissertações e teses sobre democracia participava no Brasil, para o período de 1988 a 2002. O nosso estudo aborda o período posterior, contempla a produção na forma de artigos, tem como foco específico os conselhos de políticas públicas e pretende uma avaliação mais ampla do repertório conceitual e das preocupações que constituem o campo de estudo desse objeto.

4 Os sites pesquisados foram: <http://capesdw.capes.gov.br/capesdw $>$; $<$ http:// bdtd.ibict.br/; <http://www.scielo.br/?lng=pt $>$. Fizemos um controle das repetições presentes nos bancos das dissertações e teses.

5 Excluímos os estudos sobre os conselhos locais, como os conselhos de UBS ou conselhos de escola.
} 
deveria fazer menção à palavra conselho/conselhos no título, nas palavras-chaves e/ou nos resumos ${ }^{6}$. Baseado nesses procedimentos, o universo de pesquisa foi constituído por 537 títulos.

A pesquisa coletou dados passíveis de tratamento quantitativo e qualitativo. Os resumos foram objeto de análise qualitativa, estando limitados à produção relativa aos campos das ciências sociais, saúde, serviço social e educação. Os resultados dessa análise são apresentados a seguir. Primeiramente, mostramos o perfil geral da produção sobre os conselhos, para depois nos debruçarmos sobre os campos disciplinares com o objetivo de identificar os diferentes enfoques que conferem identidade própria ao debate sobre os conselhos em cada um deles.

\section{Perfil geral da produção sobre os conselhos}

258 Como mencionado, foram mapeados 537 trabalhos produzidos sobre os conselhos entre 2000 e 2011. Nesse universo, as dissertações estão em maior número, constituindo-se em 70,0\% dos títulos, seguidas das teses $(16,0 \%)$ e dos artigos $(14,0 \%)$, como vemos na Tabela 1.

\footnotetext{
6 É importante reconhecer que o desenho da nossa amostra deixou de cobrir os livros e capítulos de livros, os quais ainda concentram parte significativa da produção sobre a temática. Podemos minimizar os impactos dessa lacuna se considerarmos que a cobertura suficientemente abrangente que se faz aqui das teses, artigos e dissertações, de certa forma, reflete temas e focos de análise contidos nas publicações de livros e coletâneas sobre o assunto. Nossa base para os artigos, o Scielo, introduz um crivo de qualidade sobre os textos analisados, o que se, por um lado, reduz a representatividade dos artigos analisados em relação ao universo produzido, por outro lado nos oferece uma boa via de acesso à literatura de ponta em cada área com impacto potencial sobre a conformação da agenda. Também o banco de dados de teses e dissertações incorporou somente os trabalhos dos bolsistas Capes, com exceção das dissertações e teses da área de história (Moraes e Oliveira, 2010), excluindo bolsistas CNPq e do sistema FAPs.
} 


\section{Tabela 1}

Distribuição dos trabalhos sobre conselhos, por tipo de produção acadêmica (2000-2011)

\begin{tabular}{|l|r|r|}
\hline Tipos de produção & $\mathbf{N}^{\mathbf{0}}$ & $\mathbf{( \% )}$ \\
\hline Artigos & 74 & 14,0 \\
\hline Dissertações & 378 & 70,0 \\
\hline Teses & 85 & 16,0 \\
\hline Total & 537 & 100,0 \\
\hline
\end{tabular}

Fonte: Elaboração própria.

Os três tipos de produção analisados apresentaram algumas particularidades quando considerados de forma específica ${ }^{7}$. Apesar dessas diferenças, é possível identificar os traços mais salientes do perfil da produção olhando para os dados como um todo. Assim, ainda que esses tipos de produção guardem singularidades, o que pode ser justificado pelas diferenças de envergadura que esses trabalhos permitem e exigem, é relevante notar que encontramos entre eles tendências semelhantes, que nos permitem identificar os saldos dessa produção de forma agrupada.

No que se refere à evolução temporal da produção ao longo do período analisado, vemos uma evolução irregular entre 2000 e 2005, com um pico em 2004, crescimento entre 2006 e 2009 e queda a partir de 2010 (ver Gráfico 1). Nos seis primeiros anos da nossa amostra (2000-2005), foram mapeados 195 títulos, e nos quatro anos seguintes (2006-2009), 255

7 De modo geral, o universo de dissertações e teses apresentou a mesma distribuição ao longo da série histórica e as maiores variações em termos de áreas de política pública abordadas. Os artigos obtiveram presença nas ciências humanas, ciências sociais aplicadas e ciências da saúde. As teses e artigos, quando comparados às dissertações, apresentam maior equilíbrio em termos de frequência entre os estudos que abordam a esfera municipal, estudos de natureza comparativa e aqueles que não tomam, em específico, uma esfera de governo para ser analisada. Ou seja, como esperado, nos artigos e teses, encontramos maior esforço no sentido de generalização teórica e de análises comparativas quando comparados com as dissertações. 
títulos. Ou seja, apesar de uma variação com tendência de queda a partir de 2010, há concentração da produção nesse último período, cujos títulos respondem por quase $46,0 \%$ da totalidade da série histórica. Quando analisamos a evolução temporal por campos disciplinares (ver Tabela 8), notamos que, à exceção do serviço social, todos os demais campos concentraram a sua produção entre 2006-2011. Como veremos mais adiante, o alto número de publicações a partir de 2006 também está relacionado com a difusão da temática dos conselhos para outros campos do conhecimento não tradicionalmente afeitos a essa discussão.

\section{Gráfico 1}

Distribuição da produção acadêmica sobre conselhos (2000-2011)

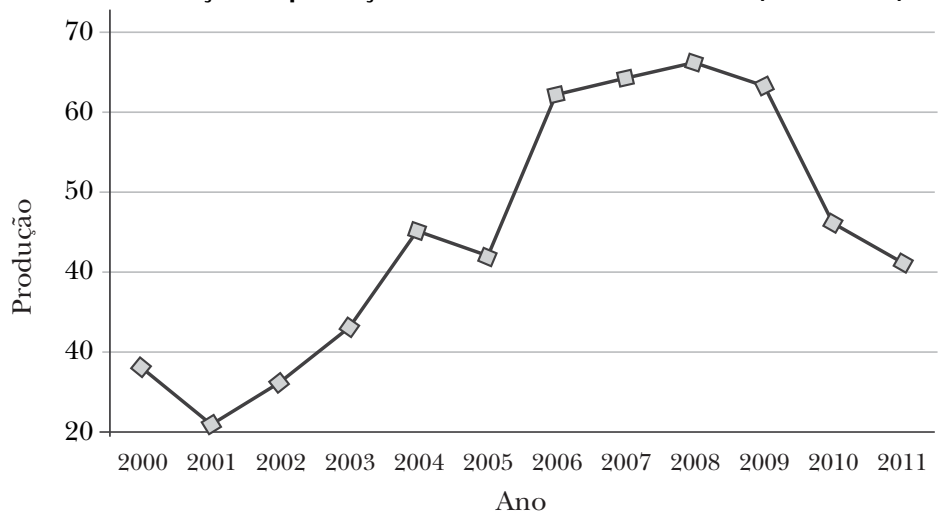

Fonte: Elaboração própria.

Assim, apesar da tendência de queda a partir de 2010, entendemos que o desempenho desse campo de pesquisa ao longo dos anos 2000, e particularmente após 2005, pode ser interpretado como um indicador da visibilidade e da crescente legitimidade que a temática foi ganhando como objeto de investigação no meio acadêmico, reforçando a ideia de que os conselhos têm se consolidado como objeto de pesquisa relevante para os pesquisadores do campo e para parte dos meios de divulgação científica. 
$\mathrm{Na}$ distribuição por grandes campos de conhecimento ${ }^{8}$, como era esperado, há maior concentração nas ciências humanas $(38,5 \%)$, seguidas de perto pelas ciências sociais aplicadas $(36,0 \%)$, e mais distante pelas ciências da saúde $(18,1 \%)$, como vemos na Tabela 2.

\section{Tabela 2}

Distribuição da produção acadêmica sobre conselhos, por grandes campos de conhecimento (2000-2011)

\begin{tabular}{|l|c|c|}
\hline Grandes campos de conhecimento & $\mathbf{N}^{\mathbf{0}}$ & $\mathbf{( \% )}$ \\
\hline Ciências humanas & 207 & 38,5 \\
\hline Ciências sociais aplicadas & 193 & 36,0 \\
\hline Ciências da saúde & 97 & 18,1 \\
\hline Multidisciplinar & 16 & 3,0 \\
\hline Ciências agrárias & 12 & 2,3 \\
\hline Ciências biológicas & 4 & 0,7 \\
\hline Engenharia & 4 & 0,7 \\
\hline Ciências exatas e da terra & 4 & 0,7 \\
\hline Total & $\mathbf{5 3 7}$ & $\mathbf{1 0 0 , 0}$ \\
\hline
\end{tabular}

Fonte: Elaboração própria.

Os demais campos respondem por apenas cerca de $7,0 \%$ do total da produção acadêmica sobre os conselhos, totalizando 40 trabalhos. Um dado interessante é que 34 desses 40 trabalhos foram produzidos a partir de 2005, indicando que essa difusão da temática é recente ${ }^{9}$, e pode estar relacionada a uma nova onda de criação de conselhos reiniciada em 2003, com a chegada do Partido dos Trabalha-

8 A divisão por grandes campos de conhecimento foi realizada de acordo com a classificação utilizada pela Capes para organização do processo de avaliação dos programas de pós-graduação do país.

9 Na nossa amostra, os estudos sobre conselhos no campo multidisciplinar aparecem, por exemplo, a partir de 2004; nas ciências biológicas, em 2006; nas ciências exatas, em 2007; e, finalmente, nas engenharias, apenas a partir de 2008. 
dores (PT) ao governo federal, fazendo emergir o interesse pelo tema em diferentes campos disciplinares.

Quando exploramos a diversidade interna aos grandes campos de conhecimento, vemos que ciências sociais, serviço social e educação concentram a produção em seus respectivos campos (ver Tabela 3). As ciências sociais respondem por $53,0 \%$ e a educação por 34,0 \% da produção de todo o campo das ciências humanas. Já o serviço social responde por $37,0 \%$ da produção nas ciências sociais aplicadas. Juntando esses três campos e as ciências da saúde, percebemos que eles respondem por $65 \%$ da produção acadêmica sobre conselhos no conjunto da nossa amostra.

\section{Tabela 3}

Campos de conhecimento que mais concentram a produção acadêmica sobre conselhos (2000-2011)

\begin{tabular}{|l|c|c|}
\hline Campos de conhecimento & $\mathbf{N}^{\mathbf{0}}$ & $\mathbf{( \% )}$ \\
\hline Ciências sociais & 110 & 31,6 \\
\hline Ciências da saúde & 97 & 27,8 \\
\hline Educação & 71 & 20,5 \\
\hline Serviço social & 70 & 20,1 \\
\hline Total & $\mathbf{3 4 8}$ & $\mathbf{1 0 0 , 0}$ \\
\hline
\end{tabular}

Fonte: Elaboração própria.

Analisamos também as áreas de politicas públicas ${ }^{10}$ que foram abordadas nos estudos. Como vemos na Tabela 4, a saúde é área que se destaca.

\footnotetext{
${ }^{10}$ Dada a necessidade de sistematização das informações, agregamos as diferentes áreas das políticas públicas levando em conta algumas questões: na categoria "Defesa de direitos", por exemplo, foram consideradas as definições jurídico-legais incluindo nesse caso os Conselhos da Criança e Adolescente, Idoso e Mulher. Já na categoria "Outros", foram incluídas todas aquelas áreas que, mesmo após uma primeira agregação, não superaram a marca de 10 trabalhos, a saber: cidades, cultura e desporto, públicos específicos, recursos hídricos e saneamento, comunicação, economia e orçamento, segurança pública, habitação e logística.
} 


\section{Tabela 4}

Área de política pública abordada na produção acadêmica sobre conselhos (2000-2011)

\begin{tabular}{|l|c|c|}
\hline Área de política pública & $\mathbf{N}^{\mathbf{0}}$ & $\mathbf{( \% )}$ \\
\hline Saúde & 186 & 34,6 \\
\hline Educação & 79 & 14,7 \\
\hline Assistência social & 60 & 11,2 \\
\hline Defesa de direitos & 50 & 9,3 \\
\hline Meio ambiente & 32 & 6,0 \\
\hline Trabalho e emprego & 18 & 3,4 \\
\hline Agricultura & 16 & 3,0 \\
\hline Comparada & 15 & 2,8 \\
\hline Sem área de abrangência especificada & 44 & 8,2 \\
\hline Outros & 37 & 6,9 \\
\hline Total & 537 & 100,0 \\
\hline
\end{tabular}

Fonte: Elaboração própria.

Considerando que os conselhos de saúde, assistência social e criança e adolescente estavam presentes em cerca de $90,0 \%$ dos municípios brasileiros já no início dos anos 2000 (cf. Gohn, 2001), são indispensáveis para o repasse de verbas do governo federal e formam a base da política social, não é de se estranhar o interesse dos analistas pelo funcionamento dos conselhos nessas áreas. Em termos da evolução temporal, constata-se maior diversificação das áreas de políticas públicas abordadas nos estudos após 2006, possivelmente um reflexo do mesmo processo ao qual já nos referimos, de expansão qualitativa dos conselhos no sistema institucional brasileiro.

No que se concerne às esferas de governo abordadas, há uma ênfase já esperada na esfera municipal em todo o 
período analisado, correspondendo a 53,0\% dos estudos. Um dado interessante a se observar na Tabela 5 é a presença de desenhos de pesquisa que comparam diferentes esferas de governo, correspondendo a 20,0\% do total de estudos produzidos. Considerando sua evolução no período investigado, constatamos que os estudos comparativos dessa natureza cresceram especialmente a partir de 2006.

\section{Tabela 5}

Esfera de governo abordada na produção acadêmica sobre conselhos (2000-2011)

\begin{tabular}{|l|c|c|}
\hline Esfera de governo & $\mathbf{N}^{\mathbf{0}}$ & $\mathbf{( \% )}$ \\
\hline Municipal & 287 & 53,0 \\
\hline Estadual & 60 & 11,0 \\
\hline Nacional & 31 & 6,0 \\
\hline Regional & 12 & 2,0 \\
\hline Metropolitana & 3 & 1,0 \\
\hline Comparada & 107 & 20,0 \\
\hline Não especificada & 37 & 7,0 \\
\hline Total & 537 & 100,0 \\
\hline
\end{tabular}

Fonte: Elaboração própria.

A análise das palavras-chave informa uma grande diversidade de aproximações temáticas pelas quais os conselhos são analisados. Nosso tratamento estatístico gerou uma codificação da qual resultaram 15 categorias, incluindo "Outros", que obteve $8,0 \%$ do total ${ }^{11}$. Dessas,

\footnotetext{
${ }^{11}$ Partimos de uma classificação abrangente das palavras-chave que resultou em 21 entradas. Analisada a frequência, buscamos reduzir a dispersão criando categorias mais amplas. Por exemplo, expressões como "democracia deliberativa", "democracia participativa", "democracia comunitária”, foram todas incluídas na categoria "democracia”, e assim por diante. Desse processo, chegamos às 15 categorias finais.
} 
definimos como critério de corte as palavras-chave que obtiveram 2,0\% ou mais de frequência, do que resultou a Tabela 6 .

\section{Tabela 6}

Frequência de palavras-chave na produção acadêmica sobre conselhos (2000-2011)

\begin{tabular}{|l|c|c|}
\hline Palavras-chave & N & (\%) \\
\hline Política pública & 415 & 35,0 \\
\hline Participação e controle social & 342 & 29,0 \\
\hline Democracia & 135 & 11,0 \\
\hline Instituições políticas e poder estatal & 99 & 8,0 \\
\hline Sociedade civil e associativismo & 81 & 7,0 \\
\hline Movimentos sociais e cidadania & 57 & 5,0 \\
\hline Representação & 31 & 3,0 \\
\hline Total & 1.191 & 100,0 \\
\hline
\end{tabular}

Fonte: Elaboração própria.

Os termos que estabelecem forte associação com os conselhos são "política pública”, "participação" e "democracia”. Juntos, eles correspondem a 75,0\% do total, evidenciando sua importância para a conformação do horizonte de sentidos ao qual os conselhos são majoritariamente referidos. Essa relação entre conselhos, políticas públicas e participação explicita um percurso muito próprio à redemocratização no Brasil, no qual o anseio pela participação da sociedade civil, comum em outros países da América Latina, aqui se traduziu no anseio por incidir sobre políticas públicas. Como inovação institucional, os conselhos selam esse encontro, essa aposta. E não é de se estranhar, portanto, a estreita união, demonstrada pela alta frequência entre participação e políticas públicas que, 
no caso das dissertações e teses, são as únicas palavras-chave que aparecem em todas as áreas de conhecimento apesar de toda a diversidade temática vista nesse universo. Encontrar essa associação de sentidos entre participação e políticas públicas no debate sobre conselhos não significa, contudo, que haja uma teorização sobre esses vínculos, o que será mais bem discutido adiante. Na categoria "participação e controle social”, a referência à "participação" representa $66,0 \%$ do total. Na categoria "instituições políticas e poder estatal", metade das referências diz respeito à descentralização e poder local, forma predominante pelas quais as questões do Estado, no geral ausentes do debate, são introduzidas. Por outro lado, chama a atenção a pouca referência à sociedade civil, conceito bastante frequente como lente para discussão dos conselhos nos anos de 1990. Também a fraca presença de referência aos movimentos sociais mostra o paralelismo entre essas duas agendas, 266 como discutido por Tatagiba (2011). Quanto à representação, cabe notar que, apesar de um debate recente, essa temática já desponta como importante marco analítico para enquadramento dos estudos dos conselhos.

A partir de 2006, percebemos também uma diversificação das palavras-chave empregadas. Isso fica evidente quando olhamos para a composição interna das 15 categorias e para as palavras-chave que, por não terem atingido $2,0 \%$ de frequência, não foram incluídas na Tabela 6. Numa perspectiva geral, algumas novas palavras-chave aparecem ou se tornaram mais frequentes após 2006, repetindo-se muitas vezes nos diferentes campos disciplinares e nos variados tipos de produção, o que sugere a existência de trânsitos e diálogos. Nessa direção, podemos citar: deliberação e democracia deliberativa, capital social, associativismo, accountability, redes sociais e redes de políticas públicas, representação e representação política, inovação institucional, inovação democrática, insti- 
tuições participativas, fóruns participatórios, governança e governança democrática. Essas palavras-chave sugerem a entrada de novos enquadramentos analíticos e repertórios conceituais, deslocando a centralidade daqueles referenciais remetidos ao ideário participativo sobre o qual se forjaram as próprias instâncias participativas no Brasil e que inspirou uma geração importante de estudos sobre conselhos. Nota-se também o emprego de palavras-chave que indicam a busca de conceitos com maior poder de generalização, com capacidade de se despregar da imediata realidade na qual se fundam, para abrigar a diversidade empírica que o fenômeno da participação expressa, como é o caso da utilização das palavras "inovação institucional”, "fóruns participatórios", "inovação democrática”, "instituições participativas".

Para finalizar essa primeira parte do artigo, chamamos a atenção para os sinais de mudança no perfil da produção a partir de 2005. No Gráfico 1, fica evidente como o ano de 2006 é ponto de referência para um crescimento significativo do número de trabalhos produzidos em nossa série histórica. Da mesma forma, quando analisamos o comportamento de algumas variáveis ao longo do período investigado, como campos de conhecimento, área de políticas públicas, esferas de governo e palavras-chave, percebemos uma mudança consistente de perfil a partir de 2006, que vai na direção de maior diversificação e pluralização.

Como já sugerimos, essa inflexão está associada, em parte, à própria criação de conselhos em novas áreas de políticas, principalmente após 2003. Ou seja, sua difusão pelo sistema político tornou os conselhos objeto de interesse para outros campos de conhecimento, o que, em alguma medida, ajuda a entender a pluralização dos repertórios conceituais e a diversificação das áreas de políticas verificadas nos estudos sobre o tema. 
A seguir, aprofundamos essa análise, nos detendo sobre os enfoques analíticos predominantes nos quatro campos de conhecimento que, ao longo de nossa série histórica, mais produziram sobre os conselhos: ciências sociais, educação, saúde e serviço social. Um olhar sobre a produção nesses campos também nos fornece pistas para compreender a inflexão detectada a partir de 2006, que expressa o próprio amadurecimento dessa agenda de pesquisa, com investimento em desenhos de investigação comparados e com maior potencial de generalização.

\section{Enfoques analíticos por (e entre) campos disciplinares}

Como mostramos anteriormente, na Tabela 3, os campos disciplinares que concentraram a produção sobre os conselhos são ciências sociais, ciências da saúde, educação e 268 serviço social ${ }^{12}$. Agora, vamos analisar como esses campos enquadram os conselhos, destacando os seus enfoques analíticos predominantes.

A discussão sobre os enfoques busca destacar os interesses que motivam as pesquisas e a forma como eles são

\footnotetext{
${ }^{12}$ São 348 títulos nesses quatro campos do conhecimento, correspondendo a $64,0 \%$ de nossa amostra, assim distribuídos: 110 nas ciências sociais, 97 nas ciências da saúde, 71 na educação e 70 no serviço social. Cabe esclarecer que selecionamos, dentro dos estudos contidos na grande área das ciências humanas, aqueles específicos das ciências sociais e educação. Do mesmo modo, selecionamos dentre aqueles contidos na grande área das ciências sociais aplicadas, aqueles do serviço social. Entretanto, os estudos da grande área das ciências da saúde foram tomados no seu conjunto, sem que áreas específicas fossem selecionadas. Isso se deu à dispersão encontrada no interior dessa grande área dos estudos provindos de várias subáreas, como saúde pública, saúde coletiva, saúde da comunidade, enfermagem e etc. Consideramos que a desagregação da produção da grande área das ciências da saúde pelas áreas que as constituem não nos permitiria captar, em linhas gerais, os contornos específicos do horizonte de problema que orienta seus estudos. E, por outro lado, o peso dos estudos dessa produção no universo total da nossa amostra exige de nossa parte uma análise mais detida sobre ela.
} 
justificados. Para lidar com a diversidade de formatos dos resumos no interior (e entre) os campos disciplinares, utilizamos como marcador central a formulação que se segue ao enunciado "o objetivo dessa pesquisa é..." ou "essa pesquisa visa...", e enunciações correlatas. Como dissemos no início desse artigo, é um primeiro esforço de aproximação que tenta explorar as potencialidades desse diálogo interdisciplinar.

Nossa motivação partiu dos recentes balanços da literatura sobre as instituições participativas, realizados nas ciências sociais (Dagnino e Tatagiba, 2007; Cunha et al., 2011; Gurza Lavalle, 2011; Silva, 2011; Vaz, 2011). Ainda que haja nuances, esses balanços apontam como tendência uma nova fase dos estudos caracterizada pela sofisticação dos métodos de análise, pelo esforço comparativo, por um olhar para além das instâncias de participação, buscando localizá-las no entorno mais amplo, pela busca por generalização dos resultados consoante a um maior investimento teórico e um enfoque mais "realista", ou seja, menos "laudatório" e "normativo". Tais mudanças teriam sido possibilitadas pelo próprio avanço da agenda de pesquisa nas fases anteriores. Esses balanços realizados nas ciências sociais também localizam os pontos cegos do debate: a relação entre participação e políticas públicas e os impactos da participação sobre o Estado. Quisemos então saber em que medida essa narrativa se aplicaria aos demais campos de conhecimento, tradicionalmente importantes para a conformação dos conselhos como objeto de análise, como as ciências da saúde, serviço social e educação. Buscamos, assim, explorar as potencialidades desse diálogo interdisciplinar.

A leitura dos resumos gerou uma primeira categorização dos enfoques, a qual foi reformulada em três etapas subsequentes. Ao final, classificamos os resumos em sete categorias, conforme o Quadro 1. 


\section{Quadro 1}

Categorização dos enfoques analíticos na produção acadêmica sobre conselhos (2000-2011)

\begin{tabular}{|c|c|}
\hline Enfoques & Objetivos dos trabalhos \\
\hline $\begin{array}{c}\text { Foco nas dinâmicas internas } \\
\text { dos conselhos }\end{array}$ & $\begin{array}{l}\text { Abordar as dinâmicas internas de funcionamento dos } \\
\text { conselhos, partindo de perguntas gerais, tais como: "como } \\
\text { se dá a participação/controle social nos conselhos". }\end{array}$ \\
\hline $\begin{array}{l}\text { Foco na análise do perfil } \\
\text { e desempenho de atores } \\
\text { específicos no interior dos } \\
\text { conselhos }\end{array}$ & $\begin{array}{c}\text { Compreender como grupos ou atores específicos (usuários } \\
\text { da saúde, ONGs, movimento popular, empresários etc.) } \\
\text { atuam como conselheiros. }\end{array}$ \\
\hline $\begin{array}{l}\text { Foco nos resultados dos } \\
\text { conselhos }\end{array}$ & $\begin{array}{c}\text { Responder, com diferentes níveis de sofisticação, a } \\
\text { pergunta "os conselhos importam?". Na maioria dos } \\
\text { casos, não há seleção de variáveis específicas para testar } \\
\text { impacto. }\end{array}$ \\
\hline Foco no debate teórico & $\begin{array}{l}\text { Interpelar teorias, criticar e/ou propor novos instrumentos } \\
\text { analíticos, ainda que contemplando ou se baseando em } \\
\text { pesquisas empíricas. }\end{array}$ \\
\hline $\begin{array}{l}\text { Foco nos processos } \\
\text { histórico-institucionais } \\
\text { mais amplos, nos quais os } \\
\text { conselhos estão inseridos }\end{array}$ & $\begin{array}{l}\text { Compreender os marcos histórico-institucionais no } \\
\text { bojo dos quais os conselhos emergem: construção da } \\
\text { democracia, revisão do pacto federativo, criação do SUS, } \\
\text { LOAS, ECA etc. }\end{array}$ \\
\hline $\begin{array}{l}\text { Pesquisas multifocais, } \\
\text { que combinam diferentes } \\
\text { dimensões de análise }\end{array}$ & $\begin{array}{l}\text { Combinar, com a mesma centralidade, diferentes enfoques, } \\
\text { por exemplo, "atores" e "dinâmicas internas". Incluem } \\
\text { desde desenhos mais sofisticados, que buscam testar } \\
\text { correlações entre dimensões de análise, até trabalhos } \\
\text { que abordam os conselhos de uma perspectiva geral, } \\
\text { contemplando dois ou mais enfoques. }\end{array}$ \\
\hline $\begin{array}{l}\text { Foco nos condicionantes } \\
\text { que influenciam, de fora, a } \\
\text { atuação dos conselhos e/ou } \\
\text { dos conselheiros }\end{array}$ & $\begin{array}{l}\text { Avaliar as dinâmicas e os resultados dos conselhos a } \\
\text { partir de dimensões externas, como projeto político dos } \\
\text { governos, padrão associativo, cultura política local etc. }\end{array}$ \\
\hline
\end{tabular}

Fonte: Elaboração própria.

A Tabela 7 informa os resultados da análise dos dados, com distribuição dos enfoques por campos de conhecimento. $\mathrm{Na}$ análise geral, vemos que o enfoque dos resultados foi o predominante, seguido do estudo das dinâmicas internas. 
Ocupando a posição final da tabela, os trabalhos com foco teórico representam apenas $9,5 \%$ do total de nossa amostra.

\section{Tabela 7}

Enfoques predominantes da produção acadêmica sobre conselhos, por campos disciplinares (2000-2011)

\begin{tabular}{|c|c|c|c|c|c|}
\hline Enfoque & $\begin{array}{c}\text { Ciências } \\
\text { sociais }\end{array}$ & $\begin{array}{c}\text { Ciências } \\
\text { da saúde }\end{array}$ & $\begin{array}{c}\text { Serviço } \\
\text { social }\end{array}$ & Educação & Total \\
\hline Resultados & 17 & 28 & 15 & 30 & 90 \\
\hline Dinâmicas internas & 18 & 16 & 19 & 15 & 68 \\
\hline $\begin{array}{c}\text { Histórico } \\
\text { institucional }\end{array}$ & 10 & 11 & 11 & 11 & 43 \\
\hline Atores & 8 & 19 & 11 & 3 & 41 \\
\hline Multifocal & 20 & 8 & 3 & 8 & 39 \\
\hline Condicionantes & 14 & 7 & 10 & 3 & 34 \\
\hline Teórico & 23 & 8 & 1 & 1 & 33 \\
\hline Total & 110 & 97 & 70 & 71 & 348 \\
\hline
\end{tabular}

Fonte: Elaboração própria.

Porém, quando olhamos para os campos disciplinares, vemos que essa leitura geral conduz a algumas distorções. Nas ciências sociais, o enfoque teórico não é o último, mas o primeiro. Nas ciências da saúde, a questão dos atores é a segunda preocupação mais presente nos estudos, e não a quarta. E na educação, a importância do enfoque dos resultados não é da ordem de $25,0 \%$ em relação ao total, mas de $42,0 \%$. Portanto, o que a Tabela 7 evidencia é a variação dos enfoques por campos disciplinares. A seguir, vamos explorar essa diversidade. Mas, antes, apenas algumas breves considerações gerais sobre os dois primeiros enfoques que se destacam como predominantes no conjunto de nossa amostra: "resultados" e "dinâmicas internas". 
De modo geral, os estudos classificados no enfoque dos resultados objetivaram saber o impacto ou a contribuição dos conselhos para a democratização da gestão das políticas públicas ou para o acesso aos direitos a elas correspondentes. Entretanto, via de regra, a preocupação com os resultados foi formulada com uma intenção muito geral de captar o "papel” dos conselhos para a democratização da gestão das políticas ou para a ampliação do acesso às políticas públicas, sem maior sofisticação teórico-metodológica. Ou seja, não identificamos nos resumos referências precisas aos problemas de natureza teórico-metodológica que avaliações acerca da efetividade necessariamente implicam. Vale notar que, no campo das ciências sociais, o reconhecimento da necessidade de superar essa lacuna na avaliação dos diferentes impactos que a participação pode produzir vem ocupando um lugar importante no debate mais contemporâneo ${ }^{13}$. O foco nas dinâmicas internas foi 272 não apenas o segundo mais presente no conjunto dos trabalhos, mas também o que mostrou maior equilíbrio entre os campos disciplinares e maior continuidade ao longo do período considerado.

Essa constatação nos permite dizer que o estudo das dinâmicas internas segue constituindo, nos quatro campos estudados, uma importante agenda de pesquisa. Os trabalhos incluídos nessa categoria olham, predominantemente, para dentro dos conselhos, amplificando dinâmicas e processos cotidianos de formação do consenso, disputa pelo poder entre os conselheiros, rotinas organizacionais, montagem da pauta de discussão, definição de procedimentos etc. Como

\footnotetext{
13 Como notam Pires et al. (2011), a magnitude adquirida pelos mecanismos e instrumentos de participação no Brasil obriga o reconhecimento da necessidade de se explicar "se" e "sob" que condições a participação e os controles sociais melhoram o funcionamento dos governos no país. Na mesma direção, para Avritzer (2011), a crescente associação no país entre "participação e políticas públicas" tornou central para analistas o problema da efetividade, ou seja, o problema de saber quais impactos os controles sociais têm produzido nas políticas públicas.
} 
se costuma dizer, é como se o pesquisador olhasse para o conselho com uma lupa, buscando responder a perguntas gerais, tais como "como se dá a participação no conselho?" ou "como é a prática do controle social no conselho?". Busca-se compreender a configuração do poder no conselho ${ }^{14} \mathrm{e}$ seus resultados sempre mantendo como referência o olhar para dentro das instâncias participativas. Encontramos dois tipos de justificativas nos estudos para preocupações dessa natureza. Nos estudos das ciências sociais, por exemplo, a investigação das dinâmicas internas dos conselhos foi justificada pelo que poderia dizer a respeito da contribuição dessas instâncias para a democracia, enquanto nos estudos das ciências da saúde, essa investigação foi vista como fundamental para avaliar a importância do conselho para a política pública de saúde. Na educação e no serviço social, a preocupação com a democracia e a política pública apareceu de forma equilibrada.

Notamos uma correspondência importante na maneira como os conselhos foram formulados como objeto de estudo nesses dois enfoques. Considerando que eles predominaram na nossa amostra, podemos dizer que uma parte importante da produção do período orientou-se pelo pressuposto geral da importância dos conselhos para as políticas públicas e/ou para a democratização dos processos decisórios. Entretanto, observamos bem pouca preocupação com a definição e a construção de instrumentos teóricos e metodológicos, para o tratamento das relações entre conselho e políticas públicas, que pudessem oferecer avaliações mais precisas e refinadas sobre suas mútuas implicações. $\mathrm{Na}$ ausência ou fraca presença desse suporte, os estudos quase sempre produziram avaliações muito gerais e quase sempre pendulares a respeitos daquelas implicações.

\footnotetext{
${ }^{14}$ Para a diferença entre agendas de pesquisa voltadas a compreender o poder no conselho e o poder do conselho remetemos a Vargas (2009).
} 


\section{Características do debate por campos disciplinares}

Para a leitura da produção por campos disciplinares, agregamos outra dimensão à nossa análise: a evolução temporal dos enfoques. Como vimos anteriormente, a análise das tendências gerais da produção acadêmica sobre conselhos evidenciou inflexões de 2006 em diante. Assim, testamos para a análise dos enfoques o peso dessa variação temporal com o objetivo de saber também quanto ela seria significativa no interior de cada campo do conhecimento. Para isso, comparamos dois períodos: 2000-2005 (P1) e 2006-2011 (P2), cujos resultados são apresentados nas Tabelas 8 e $9^{15}$.

\section{Tabela 8}

Distribuição da produção acadêmica sobre conselhos por campos disciplinares e período histórico

\begin{tabular}{|c|c|c|c|c|}
\hline Período & $\begin{array}{c}\text { Ciências } \\
\text { sociais }\end{array}$ & $\begin{array}{c}\text { Ciências } \\
\text { da saúde }\end{array}$ & Serviço social & Educação \\
\hline P1 (2000-2005) & $40,0 \%$ & $34,0 \%$ & $56,0 \%$ & $35,0 \%$ \\
\hline P2 (2006-2011) & $60,0 \%$ & $66,0 \%$ & $44,0 \%$ & $65,0 \%$ \\
\hline
\end{tabular}

Fonte: Elaboração própria.

A Tabela 8 mostra que à exceção do serviço social, todos os demais campos disciplinares concentraram a produção em P2 (2006-2011). Mas, é na Tabela 9 que encontramos os resultados mais interessantes.

\footnotetext{
${ }^{15}$ Destacamos com preto os períodos em que houve concentração de trabalhos. Na Tabela 9, no caso de distribuição regular ao longo da série histórica, optamos por preencher os dois períodos. Nos casos em branco, não se trata de ter ou não estudos, mas de enfatizar o contraste entre os períodos ou de destacar, nos casos sem preenchimento nos dois intervalos, que a produção em termos numéricos se mostrou pouco relevante para análise que estamos propondo.
} 


\section{Tabela 9}

Enfoques analíticos da produção acadêmica sobre conselhos por campos disciplinares e período histórico

\begin{tabular}{|c|c|c|c|c|c|c|c|c|c|c|c|c|c|c|c|c|c|c|c|c|c|c|}
\hline \multirow[t]{2}{*}{ Período } & \multicolumn{3}{|c|}{ 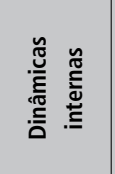 } & \multicolumn{3}{|c|}{$\begin{array}{l}\frac{y}{亠 े} \\
\frac{+}{<}\end{array}$} & \multicolumn{4}{|c|}{ 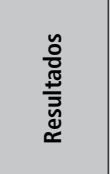 } & \multicolumn{3}{|c|}{ 茪 } & \multicolumn{3}{|c|}{ 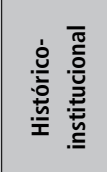 } & \multicolumn{3}{|c|}{ 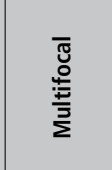 } & \multicolumn{3}{|c|}{ 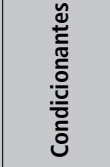 } \\
\hline & 1 & 2 & \begin{tabular}{l|l|l}
3 & 4
\end{tabular} & & 2 & $3 \mid$ & 1 & 2 & 3 & 4 & 12 & 3 & 4 & 12 & 23 & 4 & \begin{tabular}{l|l}
1 & 2 \\
$r$
\end{tabular} & 3 & 4 & 1 & & 4 \\
\hline P1 (2000-2005) & & & & & & & & & & & & & & & & & & & & & & \\
\hline P2 (2006-2011) & & & & & & & & & & & & & & & & & & & & & & \\
\hline
\end{tabular}

1 = Ciências sociais $\quad 2$ = Ciências da saúde $\quad 3$ = Serviço social $\quad 4$ = Educação

Fonte: Elaboração própria.

Embora o enfoque nas dinâmicas internas tenha sido o segundo mais presente ao longo do período considerado (ver Tabela 7), a Tabela 9 demonstra que ele foi o que apresentou maior concentração de trabalho nas quatro áreas, sendo que, na educação, essa concentração se restringiu a $\mathrm{P} 2$. O enfoque nos atores teve distribuição equilibrada em todo o período nas ciências da saúde e serviço social; não se destaca na educação e aparece como tema relevante nas ciências sociais apenas em $\mathrm{P} 2$. O enfoque nos resultados mostra uma inversão interessante entre ciências sociais, ciências da saúde e serviço social, e tem distribuição equilibrada no período, no caso da educação. O enfoque teórico não é relevante no serviço social e na educação, e aparece em P2 com concentração relativa nas ciências sociais e ciências da saúde. No enfoque histórico-institucional, a maioria dos campos disciplinares mostra concentração em P2, à exceção do serviço social. A abordagem multifocal é ausente no serviço social e tem distribuição mais equilibrada nas ciências sociais. Por fim, o enfoque nos condicionantes não é expressivo na educação, tem concentração em P2 nas ciências sociais e ciências da saúde, ao contrário do serviço social, onde aparece concentrado em P1. 
Nesse ponto, podemos avançar na análise dos traços específicos que marcam o debate dos conselhos em cada campo disciplinar.

\section{Ciências sociais}

O campo das ciências sociais apresenta uma distribuição relativamente equilibrada entre os enfoques, com predominância do debate teórico e multifocal. Vemos que, no caso do debate teórico, trata-se de uma tendência nova, com concentração a partir de 2006. Já a abordagem multifocal está igualmente distribuída em P1 e P2. Também apresenta padrão regular ao longo da série o foco nas dinâmicas internas. Já o foco nos resultados parece perder força no período, mais concentrado no primeiro (P1) e menos no segundo (P2). Também nova é a tendência de foco nos atores. Ou seja, nossa pesquisa permite afirmar que, ao longo da década, houve renovação na agenda de pesquisa nas ciências

276 sociais, que se expressa pela diversificação dos enfoques, com destaque para os enfoques teórico e nos atores, o que mostra amadurecimento dos estudos nesse campo. Essa renovação ajuda também a compreender as inflexões detectadas a partir de 2006 na produção acadêmica sobre conselhos, tal como mencionamos anteriormente.

Nessa direção, encontramos nas ciências sociais vários estudos motivados a rever/criticar conceitos e modelos teóricos conhecidos ou consagrados pela produção anterior e/ ou a proposição de instrumentais analíticos e teóricos julgados mais adequados para a compreensão dos conselhos. Esse movimento de revisão teórica e de elaboração de novas propostas analíticas apareceu particularmente nos artigos, mas o importante a notar é que os termos/questões e problemas que ele levantou se refletiu também nas dissertações e teses. Exemplos são as críticas a abordagens consideradas muito "normativas e dicotômicas" de sociedade civil e às altas expectativas que o modelo de democracia participativa 
endereçaria às instâncias participativas que, por isso mesmo, teriam obscurecido dimensões analíticas fundamentais das dinâmicas conselhistas, como a accountability e a representação política (cf. Moura e Silva, 2008; Rocha, 2011; Gurza Lavalle, Houtzager e Castello, 2006a; Lüchmann, 2007 e 2011, Abers e Keck, 2008).

O destaque aqui é a discussão do fenômeno/conceito da representação política, marca distintiva de parcelas significativas da produção mais recente sobre conselhos de políticas públicas nas ciências sociais. Essa produção trouxe um novo repertório conceitual para os estudos sobre conselhos, próprio do debate afeito à representação política, e inseriu os estudos acerca desse tema num debate mais amplo sobre a plurarização ou reconfiguração da representação política. Essa perspectiva também favoreceu a consideração dos vínculos entre as dinâmicas de representação política protagonizadas pelas organizações civis nos conselhos e nas instituições tradicionais da política (cf. Gurza Lavalle, Houtzager e Castello, 2006b).

De forma geral, pode-se dizer que os estudos sobre representação alimentam e são alimentados por uma tendência mais ampla da bibliografia recente sobre os conselhos nessa área. Trata-se de uma agenda de investigação que, em contraste com a bibliografia basicamente voltada à análise das dinâmicas internas dos conselhos, passa a chamar atenção e formular perguntas de investigação que interpelam o ambiente institucional e societal nos quais os conselhos estão inseridos. Nesse contexto, o aparecimento de determinadas palavras-chave, como movimentos sociais, governo, partidos e orçamento participativo, reflete a ampliação da lente de pesquisa para o entorno dos conselhos, o que também implica olhá-los a partir de sua relação com outros espaços institucionais de participação.

É nessa mesma direção que os estudos das ciências sociais, ao lado dos do serviço social, como se verá mais à frente, 
também se sobressaem em termos comparativos no enfoque dos condicionantes, aquele que agrupou as preocupações manifestas com os diagnósticos dos condicionantes da atuação dos conselhos. Nas ciências sociais, os estudos classificados nesse enfoque pretenderam entender os fatores que favorecem ou dificultam a ação dos conselhos segundo algumas variáveis, como o desenho institucional e a cultura política.

É digno de nota, entretanto, que esse movimento da bibliografia das ciências sociais no sentido de maior sofisticação e precisão analítica e de ampliação do olhar para o entorno dos conselhos não se reverteu em incorporação mais consistente de problemas, conceitos e ferramentas de análise que permitisse compreender as relações entre participação e políticas públicas. As preocupações referentes ao novo papel assumido pela sociedade civil nas instâncias decisórias parecem ter mediado a relação conceitual e teórica entre participação e democracia, resultando num obscurecimento ou numa

278 fraca conexão, para o período abordado, com a bibliográfica específica das políticas públicas, ou com problemas conceituais e teóricos mais afeitos aos processos estatais. Podemos dizer assim que, se a abordagem das relações entre sociedade civil e Estado deslocou-se de uma visão dicotômica para uma mais relacional, o Estado continua sendo subtematizado.

\section{Ciências da saúde}

Nas ciências da saúde, diferente do padrão nas ciências sociais, há maior concentração dos trabalhos em dois enfoques: resultados e atores. Juntos, eles compreendem $48,0 \%$ dos trabalhos produzidos na área. Em número menor estão os trabalhos preocupados com a questão dos condicionantes externos e com o debate teórico ${ }^{16}$.

\footnotetext{
${ }^{16}$ Não custa lembrar: não estamos dizendo que esses trabalhos não produzam teorização sobre seus objetos de análise. O que o dado nos diz é que seus autores, nos resumos, não definiram como objetivo de seus trabalhos a revisão ou contestação teórico-conceitual em qualquer nível.
} 
Quando consideradas as informações da Tabela 9, vemos que o enfoque nos resultados segue tendência inversa à das ciências sociais: os trabalhos classificados nesse enfoque estão concentrados na segunda metade dos anos 2000 (P2). Já o enfoque dos atores é mais bem distribuído ao longo do período e o interesse recai em dois atores em especial: os usuários e os profissionais da área de saúde, com destaque para a atuação dos enfermeiros. Essa ênfase é compreensível dado que a composição formal dos conselhos de saúde, e também da assistência social, prevê a representação de profissionais e trabalhadores de seus respectivos setores. Ou seja, diferentemente das ciências sociais, por exemplo, a própria prática dos profissionais da saúde e da assistência social está conectada com as dinâmicas conselhistas, o que pode nos ajudar a entender a significativa presença do tema dos atores em suas agendas de pesquisa. O enfoque teórico é bastante restrito e concentrado na segunda metade da década. Outro indicador de renovação da agenda é a emergência dos enfoques nos condicionantes a partir de 2007. Assim, um balanço da produção sobre os conselhos nas ciências da saúde, com base em nossos dados, sugere a manutenção de dois enfoques importantes - as dinâmicas internas e atores - e um indício de renovação da agenda com o aparecimento de novos enfoques, em particular, dos teóricos e dos condicionantes.

Nesse campo disciplinar, percebemos grande preocupação, que permeia os estudos nos diferentes enfoques, em entender os conselhos atrelados à sua importância para o SUS (Sistema Único de Saúde). Vale notar, inclusive, a forte presença dos estudos desse campo na amostra, em especial na forma de artigos, o que revela o prestígio do tema conselhos nos seus periódicos especializados. E destacar que, dos 74 artigos de nossa amostra, 35 são do campo da saúde. 
Vianna, Cavalcanti e Cabral (2009, p. 220), em um dos artigos que integra a amostra, já haviam notado "a pujante literatura na área de saúde coletiva", produzida para avaliar o cumprimento da exigência instituída pelo SUS: "de dar voz à chamada sociedade civil" nos conselhos da área. Para entender a presença marcante desse campo de conhecimento na produção aqui considerada (como o próprio interesse dos pesquisadores de forma geral na política de saúde), temos de levar em conta, como nos informa Teixeira (2013), que foi nessa área que "o discurso da participação por dentro de uma política pública" teve sua origem no Brasil. De fato, o SUS tornou-se o modelo a ser seguido por outras áreas no que diz respeito à construção de um sistema propriamente dito de participação e controle social, orientado pelo princípio da descentralização e com presença em todos os níveis federativos.

No período investigado, foi possível perceber os reflexos 280 na produção das ciências da saúde do ideário participativo do qual resultou o SUS, que se forjou na conjunção das experiências dos conselhos populares de saúde em São Paulo na década de 1970 e do Movimento Sanitarista da década seguinte - ambos influenciados pelas ideias de Educação Popular, de Paulo Freire, e da Teologia da Libertação, da Igreja católica. Conforme Ana Cláudia Chaves Teixeira (2013), foi nos conselhos populares de saúde que se forjaram as propostas pioneiras de combinação de luta autônoma e participação institucional, ainda que em torno dessa combinação tenha se constituído um debate marcado por tensões, dúvidas e divergências. Também no caso do Movimento Sanitarista, ainda que nuances estivessem presentes no seu interior, as reivindicações que prevaleceram ao longo da década de 1980 defendiam uma "participação popular autêntica” nas decisões de políticas de saúde e se contrapunham tanto a uma visão empresarial como estatizante e técnica de produção de políticas na área. 
Para Teixeira, no campo dos atores em jogo, a década de 1990 foi marcada pela análise dos efeitos dessa aposta institucional, seus limites e potencialidades. E a produção das ciências da saúde na década de 2000 reflete essa avaliação. Trata-se de uma produção fortemente enquadrada pela associação das seguintes palavras-chave, que foram as mais frequentes nos artigos, dissertações e teses: participação, controle social e políticas públicas. Essa associação, em larga medida, é elaborada nos marcos de uma expectativa de que os conselhos promovam um empoderamento popular ou cidadão, o que fornece os parâmetros para seu conhecimento e avaliação na produção das ciências da saúde. Vários trabalhos classificados no enfoque dos atores revelaram preocupações dessa natureza. Uma parte significativa dos estudos enfatizou os processos de formação "política e técnica" dos atores sociais como "variável" ou como "indicador conclusivo", importante na compreensão dos conselhos e do controle social na política de saúde, tendo em vista exatamente a preocupação com o empoderamento. Na produção que integra nossa amostra, para Bogus et al. (2003), por exemplo, a preocupação com a formação política e a capacitação técnica das lideranças sempre existiu no movimento de saúde. A capacitação foi vista nesses estudos como condição para o efetivo controle social na área da saúde, como condição de apropriação por parte de lideranças e usuários de um saber técnico que propicia maior equilíbrio de poder no interior dos conselhos (cf. Cotta, Cazal e Rodrigues, 2009).

Nesse sentido, é digno de nota que as dinâmicas internas dos conselhos foram, assim, quase sempre analisadas sob a perspectiva das preocupações relativas à distribuição interna de poder entre os diferentes grupos representados nos conselhos. Variáveis como composição dos conselhos, grau de informação dos conselheiros, dados socioeconômicos dos conselheiros, regras institucionais, entre outros, foram utilizadas para diagnosticar as assimetrias e exclusões 
existentes nesses espaços. Essas variáveis foram analisadas tendo em vista sua influência para promover/dificultar o ideal elaborado desde o movimento da reforma sanitária brasileira. É com essa mesma preocupação que vários estudos desse campo também manifestaram apreensões relativas aos resultados dos conselhos para a política pública, com a mensuração de algum nível de efetividade.

\section{Educação}

Os estudos da educação se destacam pela ênfase no debate sobre os resultados. Esse enfoque responde por quase a metade de toda a produção nesse campo, seguido do enfoque das dinâmicas internas. Juntos, os dois enfoques representam mais da metade da produção. Interessante também perceber que a educação é a área que menos abordou a temática dos atores. A Tabela 9 mostra que, nesse campo, o enfoque nos resultados é não apenas o mais frequente, mas também

282 o mais bem distribuído ao longo de todo o período. Nos outros campos disciplinares, o foco nas dinâmicas internas está mais concentrado no segundo período (P2). Aliás, diferente do serviço social, o grosso da produção está concentrado no pós-2006, quando novos enfoques se destacam: o histórico-institucional e as abordagens multifocais. Isso nos leva a concluir que a educação é um campo disciplinar cujo olhar sobre os conselhos se dá sob uma perspectiva menos diversa do que nos outros campos, com grande concentração nos enfoques dos resultados e nas dinâmicas internas, mas com tendência no período mais recente de incorporação principalmente do enfoque histórico-institucional.

No que diz respeito ao enfoque nos resultados, embora o problema metodológico apontado anteriormente persista no caso da educação, notamos aqui maior esforço em definir as categorias a serem investigadas. De um lado, vários estudos desse campo quiseram saber dos impactos pedagógicos dos conselhos, em termos dos aprendizados que eles geram 
para os seus participantes. De outro lado, encontramos também vários estudos que pretenderam avaliar o impacto dos conselhos na normatização da política pública de educação, tema que adquiriu grande importância para essa área de política.

É esse o tema que responde pela importância que assumiu nessa área também o enfoque histórico-institucional. $\mathrm{Na}$ educação, de um lado, os conselhos foram analisados como produto das reivindicações por participação inscritas na Constituição Federal, que determinou também para essa área de política o princípio da gestão democrática, materializado na LDB (Lei de Diretrizes Básicas da Educação: Lei $n^{\circ}$ 9394/96). De outro, eles também foram percebidos como fruto das políticas de descentralização e municipalização postas em prática durante os anos de 1990, no âmbito mais amplo da reforma do Estado realizada pelo governo de Fernando Henrique Cardoso. Em vários trabalhos, encontramos análises das sintonias e/ou das contradições que marcam o encontro daqueles dois processos que impulsionaram a criação dos conselhos na educação. Do mesmo modo, encontramos trabalhos que procuraram compreender as tensões do encontro histórico das demandas por participação na gestão da educação, de um lado, e as orientações de descentralização oriundas de organismos internacionais para essa área, de outro, que estariam sintonizados com um projeto de desoneração estatal da responsabilidade sobre as políticas de educação.

Em um dos trabalhos que compõem a amostra dessa pesquisa, Souza e Vasconcelos (2006) também já haviam notado a ênfase dos estudos sobre os conselhos da área de educação nas discussões sobre os processos, planos e projetos de descentralização e municipalização da educação, que foram propostos e implementados nessa área ao longo das últimas décadas. Esses autores mapearam a produção acadêmica sobre os conselhos da área da educação de 1996 
e 2002, concluindo que, em muitos trabalhos, o tema dos conselhos aparecia de forma secundária em face da centralidade conferida àqueles processos nas análises. De fato, nossa amostra não apenas corrobora essa conclusão como possibilita atestar que esse tipo de abordagem na educação responde também pelo aumento da produção desse campo sobre conselhos no último período, como sinaliza a Tabela 9. Nessa direção, vale registrar que, nos artigos publicados nesse campo, a palavra-chave participação obteve uma frequência pequena, enquanto as que se referiram a planos e políticas públicas ocuparam uma posição mais destacada, seguidas das relacionadas a descentralização, leis orgânicas municipais e municipalização.

\section{Serviço social}

No caso do serviço social, o enfoque nas dinâmicas internas é o mais presente ao longo do período considerado, seguido 284 dos enfoques nos atores, conforme já mencionado anteriormente, e do enfoque nos marcos históricos e institucionais. Vale notar que o enfoque nos resultados, segundo mais frequente, parece seguir um padrão de esgotamento: no segundo período (P2), poucos trabalhos foram categorizados nesse enfoque. Assim como o enfoque nos condicionantes, que não tem trabalhos nos anos de 2009, 2010 e 2011. Nesse campo, chama a atenção também a quase ausência de trabalhos no enfoque teórico. Em termos de tendência, portanto, o serviço social manteve dois enfoques mais regulares ao longo do período - dinâmicas internas e atores -, mas, diferente das outras áreas, não incorporou novos enfoques à sua agenda, o que parece indicar certo enfraquecimento da própria área de estudos sobre os conselhos. Nesse sentido, quando comparamos a produção em P1 (2000-2005) com P2 (2006-2011), temos que o serviço social é o único campo de conhecimento que teve queda na produção total sobre conselhos, como mostra a Tabela 8 . 
Vale ainda destacar que os estudos do serviço social classificados no enfoque histórico-institucional nos legaram um importante conhecimento sobre a relação dos conselhos com os marcos legais que, desde a Constituição de 1988, vêm normatizando as políticas públicas. No caso desse campo, trata-se de um conhecimento produzido, em particular, para a assistência social ${ }^{17}$. Sob essa perspectiva, os conselhos foram quase sempre abordados como instrumentos fundamentais e constitutivos do deslocamento da assistência social do terreno da filantropia para o terreno próprio da política pública. Nessa chave, os conselhos foram vistos como expressões de uma "nova institucionalidade", como "espaços públicos" ou "esferas públicas" de publicização de interesses e mediação "das relações entre Estado e sociedade civil” (cf. Silva, 2000; Souza, 2001; Castro, 2001; Oliveira, 2003; Brisola, 2003; Bredemeier, 2003; Emrick, 2008). O pensamento de Antonio Gramsci foi bastante citado como inspirador do repertório conceitual das expressões "esferas públicas", "espaços públicos" e "relações entre Estado e sociedade civil”. Podemos sugerir também que o livro de Raquel Raichelis - cuja primeira edição foi publicada em 1998, com o título Esfera pública e conselhos de assistência social: caminhos da construção democrática - exerceu forte influência na definição do horizonte de problemas e do repertório conceitual por meio dos quais os conselhos de políticas públicas foram construídos como objeto de estudo pelo serviço social ${ }^{18}$.

\footnotetext{
17 Podemos citar, nessa direção, a Lei Orgânica da Assistência Social (Lei $\mathrm{n}^{\circ}$ 8.742), de 1993, o Sistema Único de Assistência Social, aprovado pela IV Conferência Nacional da área realizada em 2003 e a Política Nacional de Assistência Social, aprovada em 2004 pelo Conselho Nacional de Assistência Social, que definiu e detalhou os conceitos referentes à gestão dessa política, os direitos e usuários que ela deveria abranger.

${ }^{18}$ É importante mencionar que, para além desse campo, o livro de Raichelis constituiu-se em importante referência na bibliografia brasileira sobre conselhos de políticas públicas.
} 
Importante registrar que, nos estudos do serviço social, o foco mais específico nos encontros/tensões entre o projeto político associado aos impulsos democratizantes advindos da Constituição e o projeto político vinculado às reformas neoliberais apareceu de forma um pouco distinta do da educação. Mais do que conformar seu contexto histórico, nesse campo disciplinar os projetos políticos, ou suas tensões e disputas mais precisamente, foram analisados como fatores determinantes das dinâmicas e dos resultados dos conselhos, o que nos fez incluir esses trabalhos no enfoque dos condicionantes. A coletânea organizada por Evelina Dagnino (2002) reforçaria e ampliaria a influência do repertório conceitual dos projetos políticos nos estudos sobre conselhos. Encontramos nos estudos do serviço social bastante presente o argumento contido naquela coletânea, de que a construção da democracia na América Latina estaria marcada pelos desafios decorrentes da confluência perversa entre aqueles projetos 286 políticos. Seguindo as linhas mais gerais desse raciocínio, os estudos desse campo analisaram os impactos negativos do neoliberalismo sobre o processo de reconhecimento da assistência social como política pública.

A análise dos trabalhos produzidos no país entre 2000 e 2011 sobre conselhos de políticas públicas mostrou que esse é um tema pujante de pesquisa. Nesse período, em função do próprio espraiamento dos conselhos pelo sistema político brasileiro, essas instâncias passaram a receber a atenção de novos campos disciplinares, como engenharias, ciências exatas, biológicas e o campo multidisciplinar. Em três dos quatro campos que mais produzem trabalhos sobre esse tema, ciências sociais, ciências da saúde e educação, notamos que a maior parte dos trabalhos se concentra na faixa temporal posterior a 2006, indicando uma tendência de 
crescente visibilidade e de consolidação desse objeto como tema de investigação.

Acompanhando esse crescimento, notamos também que, a partir de meados dos anos 2000, há importantes inflexões nessa agenda de pesquisa. Verificamos que há presença predominante na nossa amostra de estudos focados na esfera de governo municipal e na área de política pública em saúde. Entretanto, a partir de 2006, detectamos uma tendência de crescimento dos estudos de natureza comparativa e de maior pluralização nas escolhas das áreas de políticas investigadas, bem como de estudos que não selecionaram especificamente uma área, o que sugere aumento de trabalhos de natureza teórica. Essas inflexões nos levam a pensar em uma tendência de amadurecimento dos estudos sobre o tema, com esforços de investigação que visam a maiores graus de generalização e com desenhos de pesquisa mais sofisticados.

A partir do mesmo ano, percebe-se também pluralização nas palavras-chave utilizadas, o que indica a entrada, nesse campo de estudos, de novos repertórios conceituais e enquadramentos analíticos para além daqueles remetidos ao ideário participativo sobre o qual se forjaram as próprias instâncias participativas no Brasil. Isso não deve obscurecer, entretanto, a importância desse ideário para os estudos sobre os conselhos. Como mostramos, as palavras-chave que mais aparecem associadas nesses estudos são "política pública", "participação" e "democracia”. Deduzimos que essa associação traduza, em larga medida, os anseios endereçados aos conselhos, quais sejam, de promover a qualidade da democracia ou seu aprofundamento com a inserção de atores da sociedade civil nos processos decisórios. As fontes desse anseio encontram-se no ideário participativo construído e (re)afirmado no processo de redemocratização brasileira, fenômeno que também se fez presente em outros países da América Latina. 
Entretanto, a associação encontrada nas palavras-chave entre conselhos, democracia e políticas públicas não esteve suficientemente acompanhada pelo esforço de uma teorização sobre os modos pelos quais se dão e se processam a relação entre essas palavras e conceitos. A despeito das importantes inflexões que detectamos na agenda de estudos sobre conselhos e que sugerem amadurecimento desse campo de investigação, essa é uma das lacunas importantes diagnosticada para o período investigado. Uma parcela significativa dos estudos de nossa amostra partiu do pressuposto geral da importância dos conselhos para as políticas públicas, mas careceu de instrumentos analíticos e recursos metodológicos que propiciassem avanço no entendimento de suas mútuas implicações. De forma particular, essa lacuna foi verificada nos estudos classificados nos enfoques dos resultados e das dinâmicas internas, que também foram os dois enfoques mais presentes em nossa amostra. Sugerimos 288 que o peso das dissertações, que chega a 70,0\% da amostra, explique a presença significativa de estudos dessa natureza.

De outro lado, os trabalhos classificados no enfoque histórico-institucional, o terceiro mais presente na amostra, nos legaram um rico acúmulo de conhecimento sobre os contextos políticos e institucionais e sobre as trajetórias específicas de políticas públicas no interior das quais a criação e o funcionamento dos conselhos ganham inteligibilidade. Aqui notamos diferenças entre os campos disciplinares. Por exemplo, nas ciências sociais, a preocupação com os marcos históricos foi informada, sobretudo, pela intenção de compreender os conselhos no quadro mais amplo do processo de construção democrática no Brasil. Nas ciências da saúde, os conselhos foram inseridos na narrativa de construção do SUS.

Notamos, assim, que há diferenças entre os campos disciplinares em relação à maneira como o debate sobre os conselhos ocorre no interior de cada um deles; e que essas 
diferenças precisam ser reconhecidas, pois nos fornecem pistas de entendimento para as inflexões detectadas a partir de 2006 nos estudos sobre esse tema. Como vimos, três dos quatro campos de conhecimento que mais produzem sobre conselhos diversificaram, a partir daquele ano, suas lentes de investigação por motivações específicas, que conformam suas respectivas agendas e comunidades científicas. Ainda que não nos seja possível explorar, com os dados que temos, mais profundamente tais motivações, a leitura dos resumos de toda a produção à luz das Tabelas 8 e 9 nos permitem tecer algumas considerações a respeito.

Nas ciências sociais, percebemos um movimento de revisão conceitual e de abordagem teórica dos conselhos em direção a um conhecimento de natureza mais verticalizada. Assim, se, em uma visão de conjunto da amostra, foi fraca a ênfase no debate teórico, nas ciências sociais ela foi, ao contrário, predominante, com estudos voltados a rever e propor novos modelos analíticos e novos repertórios conceituais para a compreensão dos conselhos. No contexto desses estudos, ganhou projeção temática e conceitual o debate sobre o fenômeno da representação política nas instâncias participativas. Porém, a renovação teórica e conceitual encontrada nesse campo não incorporou um diálogo mais efetivo com a literatura sobre políticas públicas, de forma a favorecer uma compreensão mais ampla dos impactos da participação sobre a capacidade de resposta estatal.

No caso da saúde, da educação e mesmo do serviço social, ficou muito evidente como a trajetória das políticas públicas correspondente àqueles campos - e às suas respectivas demandas e momentos históricos -, impacta a conformação do conhecimento sobre os conselhos e responde por tendências próprias inerentes a tais estudos. Não à toa, portanto, que encontramos grande incidência de estudos focados em atores específicos no serviço social e na saúde. Nesse caso, o interesse dos estudos foi 
entender como o usuário dessas políticas participa dos conselhos, mas também como atuam nessas instâncias os próprios profissionais do serviço social e da saúde, já que os conselhos de saúde e assistência social reservam cadeiras para os trabalhadores do setor. Assim, o fato de a prática de seus profissionais estarem conectadas diretamente aos conselhos parece ter motivado um olhar específico para esse objeto nos campos das ciências da saúde e do serviço social.

Nossa análise indica que, nas ciências da saúde, ao longo do período estudado, os enfoques nas dinâmicas internas e em atores específicos mantêm uma importante regularidade, ao mesmo tempo que há indícios de renovação da agenda vistos no aparecimento de novos enfoques, em particular dos enfoques teóricos, dos condicionantes do funcionamento e dos resultados dos conselhos. Como tendência, os estudos desse campo buscam, assim, uma 290 avaliação da forte aposta na participação institucional realizada pelos atores vinculados à saúde - profissionais, pesquisadores, movimentos sociais - para essa área de política pública.

Na educação, verificamos grande concentração de estudos com foco nos resultados e nas dinâmicas internas dos conselhos, mas com grande tendência de pluralização, principalmente com a incorporação de estudos enfocados em marcos históricos. Sugerimos que essa pluralização resulta em larga medida da preocupação específica de se compreender os impactos das reformas institucionais que vigoraram no período sobre essa área de política pública.

Finalmente, no serviço social, detectamos dois enfoques mais regulares ao longo do período - análise da dinâmica interna e atores -, mas, diferente dos outros campos, esse não incorporou novos enfoques à sua agenda, fato que nos leva à hipótese de enfraquecimento dos estudos sobre conselhos nesse campo. 
Como dissemos no início desse artigo, esse esforço de análise que valoriza o diálogo interdisciplinar se fez a partir de nosso campo de atuação, as ciências sociais. Consideramos que o desdobramento dessa agenda a partir de outras perspectivas nos permitirá seguir de forma mais efetiva no conhecimento da relação entre a especificidade das comunidades científicas e o posicionamento dos conselhos como área de estudos, bem como na exploração dos pontos de contato e das contribuições mútuas advindas do diálogo interdisciplinar.

\section{Carla Almeida}

é professora do Departamento de Ciências Sociais da Universidade Estadual de Maringá e pesquisadora do Núcleo de Pesquisa em Participação Política (Nuppol/UEM).

\section{Domitila Costa Cayres}

é doutoranda do Departamento de Sociologia Política da Universidade Federal de Santa Catarina e membro do Núcleo de Pesquisa em Movimentos Sociais (NPMS/UFSC).

\section{Luciana Tatagiba}

é professora do Departamento de Ciência Política da Universidade Estadual de Campinas (Unicamp) e coordenadora do Núcleo de Pesquisa em Participação, Movimentos Sociais e Ação Coletiva (Nepac/Unicamp).

\section{Bibliografia}

ABERS, R. N.; KECK, M. E. 2008. "Representando a diversidade: Estado, sociedade e 'relações fecundas' nos Conselhos de Políticas Públicas”. Cadernos CRH [on-line], v. 21, n. 52, pp. 99-112.

ARANTES, R. B.; REIS, B. P. W. 2010. "Instituições políticas e controles democráticos: o paradoxal exercício simultâneo do poder e de sua contenção”. In: MARTINS, C. B.; LESSA, R. (orgs.). Horizontes das Ciências Sociais no Brasil: Ciência Política, v. 3. São Paulo: Anpocs. 
AVRITZER, L. 2011. "A qualidade da democracia e a questão da efetividade da participação”. In: PIRES, R. R. C. (org.). Efetividade das instituições participativas no Brasil: estratégias de avaliação. Brasília: Ipea.

BOGUS, C. M. et al. 2003. "Programa de Capacitação Permanente de Conselheiros Populares de Saúde na cidade de São Paulo”. Saúde e Sociedade, v. 12, n. 2, pp. 56-67.

BRASIL. SECRETARIA-GERAL DA PRESIDÊNCIA DA REPÚBLICA. 2011. Democracia Participativa - Nova relação do Estado com a sociedade (2003-2010). Brasília: Secretaria-Geral da Presidência da República. Disponível em: <http://issuu.com/secretariageralpr/docs/ democraciaparticipativa_web>. Acesso em: 29 mar. 2015.

BREDEMEIER, S. M. L. 2003. Conselho Municipal: a ampliação do espaço público para o idoso. Tese de doutorado em Serviço Social. Porto Alegre: PUC-RS.

BRISOLA, E. M. A. 2003. Cultura política e conselhos de assistência social: o caso do Vale do Paraíba. Tese de doutorado em Serviço Social. Porto Alegre: PUC-RS.

CASTRO, A. T. B. 2001. A construção da esfera pública de assistência social no Rio de Janeiro: limites e possibilidades. Tese de doutorado em Serviço Social. São Paulo: PUC-SP.

292 COTTA, R. M. M.; CAZAL, M. M.; RODRIGUES, J. F. C. 2009. "Participação, controle social e exercício da cidadania: a (des) informação como obstáculo à atuação dos conselheiros de saúde”. Physis [on-line], v. 19, n. 2, pp. 419-38.

CUNHA, E. S. M. et al. 2011. "Uma estratégia multidimensional de avaliação dos conselhos de políticas: dinâmica deliberativa, desenho institucional e fatores exógenos”. In: PIRES, R. R. C. (org.). Efetividade das instituições participativas no Brasil: estratégias de avaliação. Brasília: Ipea.

DAGNINO, E. 2002. Sociedade civil e espaços públicos no Brasil. São Paulo: Paz e Terra.

DAGNINO, E.; TATAGIBA, L. 2007. Democracia, sociedade civil e participação. Chapecó, RS: Argos.

EMRICK, G. K. 2008. Uma análise sobre a inserção de assistentes sociais como técnicos de referência do conselho municipal de assistência social da cidade do Rio de Janeiro. Dissertação de mestrado em Serviço Social. Rio de Janeiro: UFRJ.

GOHN, M. G. 2001. Conselhos de políticas públicas e participação política. São Paulo: Cortez.

GUGLIANO, A. A. 2005. "O impacto das democracias participativas na produção acadêmica no Brasil: teses e dissertações (1998-2002)”. BIB, n. 59, pp. 43-60. 
GURZA LAVALLE, A. 2011. Participação: valor, utilidade, efeitos e causas. In: PIRES, R. R. C. (org.). Efetividade das instituições participativas no Brasil: estratégias de avaliação. Brasília: Ipea.

GURZA LAVALlE, A., HOUTZAGER, P. P.; CASTELLO, G. 2006 a. "Democracia, pluralização da representação e sociedade civil". Lua Nova, n. 67, pp. 49-103.

GURZA LAVAlle, A.; HOUTZAGER, P. P.; CASTEllo, G. 2006 b.

"Representação política e organizações civis: novas instâncias de mediação e os desafios da legitimidade”. RBCS, v. 21, n. 60, pp. 43-66.

IPEA/DIEST - Instituto de Pesquisa Econômica Aplicada, Diretoria de Estudos e Políticas do Estado, das Instituições e da Democracia. 2013. Conselhos nacionais: perfil e atuação dos conselheiros. Brasília: Ipea (Relatório de pesquisa).

LÜCHMANN, L. H. H. 2007. "A representação no interior das experiências de participação”. Lua Nova, n. 70, pp. 139-70. . 2011. "Associações, participação e representação. Combinações e tensões". Lua Nova, n. 84, pp. 353-64.

MORAES, A. F.; OLIVEIRA, T. M. 2010. "Experiências relacionadas ao levantamento de teses e dissertações”. Informação Ẽ Sociedade: Estudos, João Pessoa, v. 20, n. 1, pp. 73-81.

MOURA, J. T. V.; SILVA, M. K. 2008. "Atores sociais em espaços de ampliação da democracia: as redes sociais em perspectiva”. Revista de Sociologia e Política, v. 16, pp. 43-54.

OLIVEIRA, N. G. 2003. Cultura política como determinante histórico da participação social: o Conselho da Saúde de Ipatinga - MG. Dissertação de mestrado em Serviço Social. Rio de Janeiro: UERJ.

PIRES, R. R. C. et al. 2011. "Em busca de uma síntese: ambições comuns e abordagens diversificadas na avaliação da efetividade das instituições participativas”. In: PIRES, R. R. C. (org.). Efetividade das instituições participativas no Brasil: estratégias de avaliação. Brasília: Ipea.

RAICHELIS, R. 1998. Esfera pública e conselhos de assistência social: caminhos da construção democrátic $a$. São Paulo: Cortez.

ROCHA, C. V. 2011. "Gestão pública municipal e participação democrática no Brasil”. Revista de Sociologia e Política [on-line], v. 19, n. 38, pp. 171-85.

SILVA, M. K. 2011. Dos casos aos tipos: notas para uma apreensão das variações qualitativas na avaliação das instituições participativas. In: PIRES, R. R. C. (org.). Efetividade das instituições participativas no Brasil: estratégias de avaliação. Brasília: Ipea. 
SILVA, S. S. S. 2000. A atuação do Conselho de Assistência Social da Cidade do Recife, frente à ofensiva neoliberal. Dissertação de mestrado em Serviço Social. Recife: UFPE.

SOUZA, M. A. V. S. 2001. O conselho municipal de saúde de Teresina e o processo de construção de uma esfera pública. Autonomia e representatividade dos usuários e profissionais de saúde. Dissertação de mestrado em Serviço Social. Rio de Janeiro: UFRJ.

SOUZA, D. B. de; VASCONCELOS, M. C. C. 2006. Os conselhos municipais de educação no Brasil: um balanço das referências nacionais (1996-2002). Ensaio: Avaliação e Políticas Públicas em Educação [on-line], v. 14, n. 50.

VAZ, A. C. N. 2011. "Da participação à qualidade da deliberação em fóruns públicos: o itinerário da literatura sobre conselhos no Brasil”. In: PIRES, R. R. C. (org.). Efetividade das instituições participativas no Brasil: estratégias de avaliação. Brasília: Ipea, 2011.

TATAGIBA, L. 2011. "Qualidade dos processos participativos: a questão dos atores e seus repertórios de ação”. In: PIRES, R. R. C. (org.). Efetividade das instituições participativas no Brasil: estratégias de avaliação. Brasília: Ipea, 2011.

TEIXEIRA, A. C. C. 2013. Para além do voto: uma narrativa sobre a democracia participativa no Brasil (1975-2010). Tese de doutorado. Campinas, SP: Unicamp.

VARGAS, S. C. (org.). 2009. Participação e saúde no Brasil. Rio de Janeiro: Fiocruz.

VIANNA, M.; CAVALCANTI, M. L.; CABRAL, M. P. 2009. "Participação em saúde: do que estamos falando?”. Sociologias, Porto Alegre, ano 11, n. 21, pp. 218-51. 


\title{
BALANCCO DOS ESTUDOS SOBRE OS CONSELHOS DE POLÍTICAS PÚBLICAS NA ÚLTIMA DÉCADA
}

\author{
CARLA ALMEIDA \\ DOMITILA COSTA CAYRES \\ LUCIANA TATAGIBA
}

Resumo: Este artigo apresenta uma revisão da literatura sobre os conselhos de políticas públicas no Brasil com base em artigos, dissertações e teses produzidos entre 2000 e 2011 com o objetivo de contribuir com a conformação das novas agendas de pesquisa na área. Na primeira parte do trabalho, traçamos um diagnóstico do perfil geral e das tendências dessa produção e, na segunda, analisamos de forma comparada a identidade do debate sobre os conselhos nos quatro campos disciplinares que mais têm produzido sobre o tema: as ciências sociais, a saúde, o serviço social e a educação. Os dados mostram que ocorreram crescimento e consolidação dessa área de estudos e que houve importantes inflexões na agenda de pesquisa no período investigado, sugerindo seu amadurecimento. Essas tendências gerais ganham, entretanto, diferentes graus, contornos e direções, dependendo dos campos disciplinares considerados.

Palavras-chave: Conselhos de Políticas Públicas; Balanço Bibliográfico; Campos Disciplinares; Políticas Públicas; Participação.

\section{REVIEW OF THE LITERATURE ON POLICY COUNCILS OVER THE LAST DECADE}

Abstract: This paper reviews Brazilian literature regarding public policy councils on different types of academic productions (articles, master's thesis and doctoral dissertations) published from 2000 to 2011 in order to contribute on shaping new research agendas to the subject. We draw a diagnosis of general profile and trends of this production and compare the debate in and across disciplinary fields that have produced more about the subject: Social Sciences, 
Health, Social Services and Education. We concluded that there were growth, consolidation and changes on the research agenda in the area of discussion within the period analyzed, suggesting the debate is ripening. These general trends gain, however, different degrees, forms and directions relying of the disciplinary fields.

Keywords: Policy Councils; Literature Review; Disciplinary Fields; Public Policy; Participation.

Recebido: 30/07/2014 Aprovado: 20/02/2015 